\title{
A COMPLEXIDADE DE HANNA EM UMA MENINA ESTÁ PERDIDA NO SEU SÉCULO À PROCURA DO PAI, DE GONÇALO M. TAVARES
}

\author{
Letícia Carvalho de Quadros \\ Mestranda em Estudos Literários pela UFPR \\ leticia.quadros95@gmail.com
}

\section{RESUMO}

O presente artigo possui como objetivo analisar a complexidade que envolve a personagem Hanna, uma das protagonistas do romance Uma menina está perdida no seu século à procura de seu pai, de Gonçalo M. Tavares. Cada personagem de uma obra apresenta-nos uma complexidade a ser desvendada. Hanna ultrapassa esse nível médio, visto que possui Síndrome de Down, e na maior parte do romance comunica-se apenas com movimentos da cabeça, concordando ou negando. Analisaremos, dessa forma, como isso aumenta a complexidade de Hanna, já que seus atos e expressões podem ser interpretadas de diversas formas. Para isso, além do romance em questão, utilizaremos algumas teorias a respeito do personagem no romance, como Candido (2007), Forster (2005), e Wood (2012).

Palavras-chave: personagem, Hanna, complexidade.

\begin{abstract}
In this article we aim to analyze the complexity that surrounds the character Hanna, one of the protagonists of the novel A girl is lost in her century in search of her father, Gonçalo M. Tavares. Each character in a work presents a complexity to be unraveled, and Hanna surpasses that middle level, since she has Down's Syndrome, and most of the novel communicates only with head nodding, nodding or denying. We will then analyze how this increases Hanna's complexity, since her acts and expressions can be interpreted in a number of ways. For this, in addition to the novel in question, we will use some theories about the character in the novel, such as Candido (2007), Forster (2005), and Wood (2012).
\end{abstract}

Keywords: character, Hanna, complexity.

UMA BREVE REFLEXÃO SOBRE A PERSONAGEM

Estudar uma personagem nem sempre é tarefa fácil. Vários teóricos já discorreram sobre o assunto, e uma das teorias mais conhecidas é a de FORSTER (2005). Vejamos o que ele nos fala sobre personagens em geral: 
Ele é criado na mente de centenas de romancistas diferentes, que têm métodos contraditórios de gestação, de modo que não podemos fazer generalizações. Ainda assim, podemos dizer alguma coisa a seu respeito. Geralmente, ele nasce de repente, é capaz de morrer aos poucos, não precisa de muito alimento nem de sono, e se ocupa incansavelmente de relacionamentos. E - o que é mais importante - podemos saber a respeito dele mais do que sobre qualquer outra criatura que conheçamos, porque seu criador e seu narrador são um só ser (FORSTER, 2005, p.51).

Sendo assim, segundo Forster, podemos conhecer muito melhor um personagem do que um ser humano real. Isso porque o personagem é um ser escrito e o seu criador sabe tudo sobre ele. O conhecimento que o autor tem da sua personagem é "muito mais coeso e completo (portanto mais satisfatório) do que o conhecimento fragmentário ou a falta de conhecimento real que nos atormenta nas relações com as pessoas (CANDIDO, 2007, p.64). Podemos dizer que compreendemos melhor uma personagem porque as informações a respeito dela estão melhor organizadas do que o conhecimento esparso que temos de uma pessoa na vida real.

Além disso, há algo próprio do romance que o torna capaz de nos informar muito mais coisas do que qualquer pessoa: "ao contrário do cinema, por exemplo, o romance pode nos revelar o que pensa um personagem" (WOOD, 2012, p. 89). Um ser real pode até tentar nos comunicar o que pensou, mas haverá nessa transmissão uma reelaboração, ou até uma alteração do conteúdo do pensamento. Já no romance podemos ter acesso ao pensamento puro do personagem, se o narrador optar por isso. Mas não podemos delimitar a definição de personagem abordando apenas o seu pensamento:

se disser que um personagem parece estar ligado à consciência, a um funcionamento mental, os vários exemplos magníficos de personagens que parecem pensar muito pouco, que raramente aparecem pensando, vão se rebelar 
(Gatsby, Capitão Ahab, Becky, Sharp, Widmerpool, Jean Brodie) (WOOD, 2012, p. 94).

Portanto, podemos conhecer um personagem através de diferentes meios: através de suas falas pessoais, das falas de outros, e através do discurso do narrador, que, como dissemos anteriormente, pode revelar o que determinado personagem pensa, visto que "o romance é o grande virtuose da excepcionalidade: sempre se esquiva às regras que lhe são ditadas" (WOOD, 2012, p. 95). Justamente por isso encontramos nos romances diferentes tipos de personagem. Forster (2005) divide os personagens entre planos e redondos. Os personagens planos "são ora chamados de tipos, ora de caricaturas. Na sua forma mais pura, são construídos ao redor de uma ideia ou qualidade simples; quando neles há mais do que um fator, apreendemos o início de uma curva na direção dos redondos" (FORSTER, 2005, p. 58). Ao contrário dos planos, os personagens redondos não podem ser resumidos em uma ideia, tornando-se assim mais complexos.

O personagem plano pode ser identificado mais facilmente, pois todo personagem que é tipo ou caricatura pertence à essa classificação. Mas nem por isso torna-se menos interessante. Como nos diz Wood (2012, p. 112), "nem por serem planos são personagens menos vívidos, interessantes ou autênticos".

No que diz respeito à complexidade:

Graças aos recursos de caracterização (isto é, os elementos que o romancista utiliza para descrever e definir a personagem, de maneira a que ela possa dar a impressão de vida, configurando-se ante o leitor), graças a tais recursos, o romancista é capaz de dar a impressão de um ser ilimitado, contraditório, infinito na sua riqueza; mas nós apreendemos, sobrevoamos essa riqueza, temos a personagem como um todo coeso ante a nossa imaginação. Portanto, a compreensão que nos vem do romance, sendo estabelecida de uma vez por todas, é muito mais precisa do que a 
que nos vem da existência. Daí podermos dizer que a personagem é mais lógica, embora não mais simples, do que o ser vivo" (CANDIDO, 2007, p.59).

Portanto, a complexidade de um personagem não pode ser ilimitada, visto que é um ser escrito, com suas delimitações. Mas, como também comenta Candido (2007), o romance moderno procurou aumentar a sensação de dificuldade do personagem, aumentando, para o leitor, a aparência de complexidade. É justamente isso que o autor faz com a personagem que aqui pretendemos analisar.

\section{O ROMANCE ESTUDADO}

Nosso objeto de análise pertence à obra Uma menina está perdida no seu século à procura do pai, de Gonçalo M. Tavares, publicada em 2014. Nesse romance contextualizado no período pós-guerra, Hanna, uma garota com Síndrome de Down, está perdida, à procura do pai. Inicialmente não sabemos em qual país ela está, mas depois que Hanna encontra Marius, que é um fugitivo, ficamos sabendo que eles se dirigem a Berlim. Portanto, o local onde Hanna se encontra com Marius ainda é desconhecido. Ela está à procura do pai, do qual não pode revelar o nome, porque diz que se revelar, terá sua língua cortada. E ele está fugindo, mas não sabemos do que ou de quem. Isso já faz do romance em si um objeto complexo de análise.

Além disso, esse romance segue uma linha apresentada em romances anteriores do mesmo autor, pois "desde Jerusalém (2006), o autor apresenta narrativas com episódios sombrios, que retratam um mundo situado num tempo pós-catástrofes do século XX" (BELTRÃO; FERREIRA; MOURA, 2016, p. 80). No tratamento que dá ao tema do preconceito nessa obra, há 
Algo muito próximo ao tratamento do medo e da loucura dado por Gonçalo em Jerusalém ou da banalidade do mal em $\boldsymbol{A}$ máquina de Joseph Walser, ambos parte da tetralogia O reino, que fecha com Um homem: Klaus Klamp e Aprender a rezar na era da técnica (SILVA, 2016).

São temas densos, que exigem atenção e cuidado. No caso da obra que aqui analisamos, a ausência de fala de Hanna abre espaço para muitas interpretações. O vazio passa a ter sentido, visto que a personagem, por si só, "é quase inacessível” (EIRAS, 2016, p. 380). Todos os personagens, nesse romance, contêm uma parcela de complexidade, pois todos eles, de alguma forma, dialogam com o período do pós-guerra. Hanna, porém, se torna ainda mais complexa porque:

Sabemos [...] que os campos de concentração executaram sumariamente centenas de milhares de pessoas com deficiências cognitivas; mesmo que Hanna seja demasiado jovem para ter enfrentado o genocídio nazi, sabemos que ela seria teria sido - uma vítima inevitável. Assim, este episódio revela-se particularmente chocante. Do mesmo modo que um velho sobrevivente quer morar num quarto chamado Terezin, assim o bem-intencionado Marius leva Hanna, uma criança com trissomia 21, até um quarto chamado Auschwitz, nome do campo onde ela teria sido inapelavelmente gaseada (EIRAS, 2016, p. 383).

Por isso, buscando entender um pouco melhor como Hanna se comporta e como é vista nesse contexto pós-guerra, passaremos agora à análise de alguns trechos do romance.

\section{A COMPLEXIDADE DE HANNA}

Hanna é uma pessoa que, se tivesse vivido durante a guerra, teria sido perseguida, visto que possui uma deficiência. Como nos mostra Eiras (2016), no trecho que acabamos de citar, ela teria sido enviada para uma câmara de gás. Além disso, quando ela é encontrada por Marius na rua, diz que está à procura do pai. Mas terá fugido de alguma instituição? Ou será que a família a abandonou por possuir uma deficiência? São muitas interpretações 
possíveis desse fato. Quando Marius a encontra, há juntamente com ela uma caixa com fichas:

Marius abriu a caixa.

Eram fichas. Em cada uma delas no topo a indicação, numa letra minúscula, APRENDIZAGEM DE PESSOAS COM DEFICIÊNCIA MENTAL. [...]

Cada ficha tinha um tópico e, depois, um conjunto de passos, actividades ou questões. Marius começou a passar algumas fichas: "EXPLORAR OBJECTOS" neste campo, o exercício número 3 era assim apresentado: “Deixar cair e voltar a agarrar um objecto"; muitas outras fichas, e eis que aparecia em grandes letras a palavra "HIGIENE", "6 - Limpar a baba, 7 - Lavar as mãos, 8 - Lavar a cara"; "Saúde e Segurança”, " 1 - INDICAR A PARTE DO CORPO QUE DÓI”. Marius pensou em como isto era difícil, não apenas para um deficiente mental, mas para todos os seres humanos, para todos os seres vivos" (TAVARES, 2015, p. 14-15, grifos do autor).

Provavelmente a garota tinha recebido essa caixa em alguma instituição que cuidava de pessoas com esse tipo de deficiência. Inclusive, Marius vai em todas as instituições que conhece, mas Hanna não pertencia a nenhuma. As fichas indicam como era guiado o aprendizado de Hanna. Mas também indicam o quanto pode ser complexo cuidar e compreender essa pessoa. Quando Marius a encontra na rua, ela tinha a primeira ficha de sua caixa nas mãos. Nela, temos as seguintes informações:

$$
\begin{aligned}
& \text { FORNECER OS SEUS DADOS PESSOAIS } \\
& \text { 1-Dizer o primeiro nome } \\
& \text { 2-Dizer se é rapaz ou rapariga } \\
& \text { 3-Dizer o nome completo } \\
& \text { 4-Dizer o nome dos pais e irmãos } \\
& \text { 5-Dizer a morada }
\end{aligned}
$$




\section{6-Dizer em que escola anda \\ 7-Dizer a idade \\ 8-Dizer o dia e o mês de aniversário \\ 9-Dizer a cor dos olhos e do cabelo}

Marius sorriu.

Perguntou.

- Qual é o teu primeiro nome?

- Hanna.

- És rapaz ou rapariga?

- Rapariga.

(ela falava atabalhoadamente, mas Marius conseguia perceber.)

- O teu nome completo?

- Não.

- Não dizes?

Ela não respondeu. [...]

Marius continuou:

- Nome dos pais e dos irmãos?

- Não.

- A morada?

- Não.

- Em que escola andas?

- Não.

Ela não parava de sorrir. Os seus nãos eram simpáticos - como se fossem sins.

- Que idade tens? 


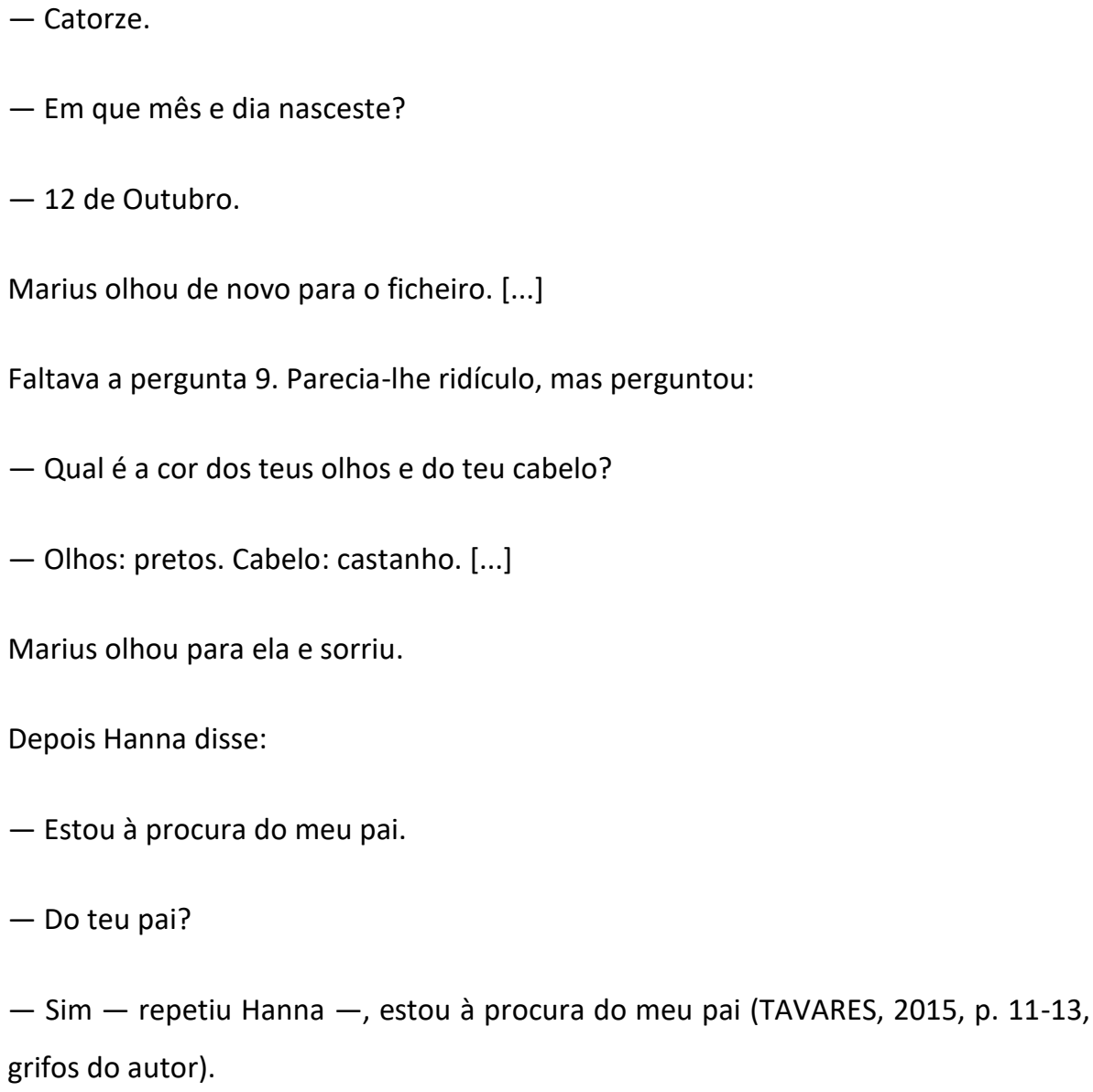

Como é possível perceber por meio do diálogo entre Hanna e Marius, ela praticamente se expressa através de simples negações ou afirmações. Uma das maiores frases que Hanna fala durante todo o romance é justamente quando diz que está procurando o pai, no fim do trecho citado acima. Mas, apesar de falar minimamente, a menina fala com tanta simpatia, demonstrando confiança e apreço por Marius. Contudo, não conseguimos saber o que o narrador quer expressar através disso. Ingenuidade por parte de Hanna? Ou uma sensibilidade da personagem, que sabe em quem confiar? Não conseguimos determinar qual interpretação é correta. Mas temos uma pista, quando analisando as fichas de aprendizagem de Hanna, Marius chega no seguinte item: "'RECONHECER SINAIS INDICADORES DE PERIGO', último passo de uma meta de aprendizagem; Marius olha para ela, sorri; ela está longe disso, não perceberá nenhum perigo" (TAVARES, 2015, p. 17). 
Percebemos o que Candido (2007) comenta a respeito do romance moderno, através do modo como o narrador nos apresenta (ou deixa de apresentar) Hanna:

O romance moderno procurou, justamente, aumentar cada vez mais esse sentimento de dificuldade do ser fictício, diminuir a ideia de esquema fixo, de ente delimitado, que decorre do trabalho de seleção do romancista. Isto é possível justamente porque o trabalho de seleção e posterior combinação permite uma decisiva margem de experiência, de maneira a criar o máximo de complexidade, de variedade, com um mínimo de traços psíquicos, de atos e de ideias (CANDIDO, 2007 , p. 59, grifo do autor).

Acontece que o narrador, em nenhum momento do romance, nos dá ao menos indícios do que Hanna está pensando, ou das ideias que tem sobre o momento em que vive, se realmente espera um dia encontrar seu pai etc. Sobre a menina, nós temos o que ela fala, que é pouquíssimo. Marius até comenta que "queria saber mais, mas ela não falava quase nada" (TAVARES, 2015, p. 16). Temos ainda o que Marius percebe, a partir da convivência com ela; e a percepção dos demais, que convivem com ela durante certo tempo, entre uma viagem e outra. Wood nos diz que conseguiremos "saber muitas coisas sobre um personagem pela maneira como ele fala, e com quem fala - como ele lida com o mundo" (2012, p.89). Mas no caso de Hanna, como dissemos anteriormente, não fazemos ideia de como ela enxerga o mundo. Mas ao menos sabemos que, por muitas vezes, não ter noção do perigo que certas pessoas podem representar, ela trata com simpatia todas as pessoas que encontra, e inclusive Marius comenta: "Grita se te dói, sorri se te agrada; mas ela sorri sempre, Hanna, como ela é simpática" (TAVARES, 2015, p. 17). Quando vão se despedir de alguém que conheceram no caminho, temos um exemplo da simpatia geral que a menina tem por todos: 
Despedimo-nos estranhamente - mal o conhecia, haviam sido apenas umas horas de conversa - com um apertado abraço na estação, e depois ele fez o mesmo a Hanna mas muitas vezes e apertando-a com tal força que me fez recear o pior, uma reacção dela imprevisível - sairão gritos, começará a mexer-se desordenadamente? Mas não: ela retribuiu como pôde com os braços gordinhos a bater repetidamente nas ancas de Fried, como se este fosse um instrumento amigável de percussão, um instrumento que, quando se batia nele, nos abraçava; e a imagem estranha [...] era que Fried, tal como eu, parecia pedir-Ihe desculpa por não ser como ela, por ser normal e por entender as coisas (TAVARES, 2015, p. 46-47).

Vê-se que Fried gostou muito de Hanna. E chega a comentar com Marius se devemos agradecer a quem abandonou a garota:

Bem, disse Fried, não sei se quem a abandonou merece o nosso ódio e a nossa vingança por ter feito a velhacaria de abandonar alguém demasiado fraco para se defender minimamente, ou se merece o nosso agradecimento.

Porque mereceria o nosso agradecimento? - tive vontade de lhe perguntar, mas estávamos a chegar a Berlim, à estação (TAVARES, 2015, p. 44-45).

Merece o agradecimento porque obriga os demais a se preocuparem com o próximo, a lidarem com o diferente, sem rejeitá-lo ou condená-lo. Mas merece o ódio por um motivo óbvio: uma pessoa totalmente indefesa de uma hora para outra passa a depender apenas de si mesma.

Mas há um personagem que não simpatiza com Hanna. Pior: vê a menina como uma aberração. Josef Berman, um fotógrafo, tem dois álbuns: um destinado a fotografar animais com algum tipo de deficiência, e outro onde coleciona fotos de pessoas com algum tipo de deficiência. Quando encontra Marius e Hanna, depois de mostrar o primeiro álbum, revela o seguinte:

A organização era idêntica, mas aquelas eram fotos de pessoas. Não de pessoas normais; depois de passar três ou quatro folhas do álbum, rapidamente percebi, não eram fotos de pessoas normais, mas sim de doentes, pessoas deficientes [...]. 
De resto, a partir de uma certa altura, o álbum, que continuava a folhear com a preocupação de Hanna não o ver, concentrava-se por completo em fotografias a deficientes com trissomia 21.

Já fotografei na Bulgária, na América, em todos os lados do mundo - disse Josef, que ia seguindo o meu olhar sobre o álbum. - São iguais, pertencem ao mesmo povo (TAVARES, 2015, p. 23-24).

Essa obsessão nos lembra claramente o nazismo. A comparação se torna ainda mais forte porque, em ambos os álbuns, "tinha sempre três fotografias: uma de frente duas de perfil. - Como os presos. - Sim - disse o homem, e riu-se" (TAVARES, 2015, p. 20). A obsessão em perseguir, nesse caso através da fotografia, pessoas por algum motivo diferente. Esse homem é incapaz de sentir compaixão por essas pessoas. Logo a seguir, Marius fala o que todos nós pensaríamos ao ver um álbum assim:

E eram, de facto, iguais. Rostos e mais rostos sorridentes, aceitando o que a vida Ihes havia dado, aceitando tudo, certamente o que aquele fotógrafo lhes havia pedido, aceitando, sem perceber ("SORRIR OU VOCALIZAR EM RESPOSTA À PRESENÇA DE UMA PESSOA OU SITUAÇÃO AGRADÁVEL"), manifestando-se incapazes de distinguir os dois lados do mundo [...] muitos deles estariam algures, ainda, perto de uma qualquer outra situação perversa que thes pareceria agradável, a sorrir, com aquele sorriso sedutor e tão ingênuo (TAVARES, 2015, p. 24-25).

Seria a (falta de) caracterização de Hanna uma indicação de falha desse romance? Acreditamos que não. Como nos diz Wood (2012):

Creio que os romances tendem a falhar não quando os personagens não são vívidos ou profundos o suficiente, e sim quando o romance em questão não nos ensina como nos adaptar a suas convenções, não desperta uma fome específica por seus personagens, por seu grau de realidade (WOOD, 2012, p.105).

Nesse caso, o romance ensina a nos adaptarmos à Hanna. Na primeira página já nos informa que Hanna é portadora de Síndrome de Down, e isso já nos alerta de que nela 
teremos uma personagem com lacunas de informações e, portanto, mais complexa. Apesar de se comunicar tão pouco verbalmente, a menina transmite vitalidade ao leitor.

Assim, a vitalidade do personagem não tem muito a ver com a ação dramática, com a coesão narrativa, nem sequer com a simples plausabilidade - e menos ainda com a probabilidade -, estando mais ligada a um sentido filosófico ou metafísico mais abrangente, nossa consciência de que as ações de um personagem são profundamente importantes, que há algo profundo em jogo, o autor ruminando sobre a face daquele personagem como Deus sobre a face das águas (WOOD, 2012, p. 109, grifo do autor).

É justamente isso que acontece, pois tudo que Hanna faz no romance, visto que age e fala pouco, adquire muita importância. A todo o momento o leitor está atento, esperando por uma fala ou uma ação da garota. Um simples não seu já adquire um significado muito maior do que um não de uma personagem que fale muito em um romance. Marius, em questão de expressão verbal, é mais ativo do que Hanna. Mas as poucas falas de Hanna são muito mais importantes do que as várias manifestações verbais dele. A simples presença dela provoca uma mudança nas pessoas que estão ao seu redor:

E a sensação que eu tinha era de que Hanna se constituía como um elemento estranho, que parecia, como Moisés, à medida que avançava, separar as águas. A sensação era de que a cidade e os seus elementos humanos - e mesmo não humanos (até as coisas fixas, os postes de electricidade) - se desviavam para um lado ou para o outro quando ela se aproximava, mas aqui, ao contrário do que sucede aquando da passagem de um homem poderoso ou de uma caravana de carros sinalizada como importante, o desvio a que Hanna obrigava as pessoas desvio concreto, físico, um metro mais para a direita ou para a esquerda - era realizado com profundo e evidente prazer, prazer que se exteriorizava, então, quase infalivelmente, por via de um sorriso naquele momento crucial, decisivo, na história das cidades (TAVARES, 2015, p. 57-58). 
Portanto, a vitalidade de Hanna está ligada a um sentido metafísico e filosófico, "que parecia, como Moisés, à medida que avançava, separar as águas" (TAVARES, 2015, p.57). Ela também é tratada com especial atenção pelos donos do hotel onde ela fica hospedada com Marius, em Berlim. Seria essa atenção o fruto de uma identificação com Hanna por parte do casal? Provavelmente. Os donos do hotel são judeus. Assim como qualquer portador de deficiência, o seu povo também foi perseguido durante a guerra. Os mimos com Hanna podem ser interpretados como uma espécie de compensação por tudo que ela já pode ter sofrido e por estar perdida, longe de sua família:

[...] era evidente que a presença de Hanna quebrara naquele casal uma série de rotinas, e Hanna era tratada principescamente - de doces a refrescos, tudo the ofereciam; o mais pequeno desejo dela era rapidamente atendido. Tratavam-na como tratariam uma pessoa importante - o director de uma instituição, o familiar mais velho e mais respeitado da família - enfim, era evidente uma agitação - que noutro contexto seria classificada como de subserviente - em redor de Hanna (TAVARES, 2012, p. 92-93).

Da mesma forma, o casal não simpatiza com Josef Berman, o fotógrafo que queria fotos de Hanna para o seu álbum:

Raffaela disse:

- Enquanto você esteve fora passou por aqui um fotógrafo. Perguntou por si... Queria fotografar a menina, disse que você tinha autorizado. Mas nós não deixamos

Fiquei sem reacção. Não sabia o que havia de dizer.

- Se quer que Ihe diga, não gostei dele... - murmurou ainda Raffaela já de costas para mim. - ... Ele disse que depois voltava a passar (TAVARES, 2015, p. 114).

É bem provável que esse homem que considera Hanna uma aberração, também considerasse assim esse casal. 
Em um determinado momento, Marius e Hanna não conseguem encontrar o quarto deles no hotel. E pela primeira vez ficamos sabendo que Hanna se assustou: Havia um silêncio absoluto e apenas se escutava a respiração de Hanna, já cansada, uma respiração agora mais ofegante - estava a perceber algo, e a ficar assustada (TAVARES, 2015,p. 131). 0 que ela não terá sentido ao ver-se perdida e sozinha, antes de Marius a encontrar?

No fim do romance, além de não conseguir encontrar o pai, Hanna perde-se de Marius, em meio a uma multidão que estava participando de uma manifestação:

[...] e as mãos de Marius e Hanna, que tinham estado sempre apertadíssimas - os dois, de maneira diferente, estavam assustados -, as mãos começaram então, lentamente, como que a relaxar, diminuindo a força e a tensão entre elas [...] e a mão, sentiu Marius, de repente estava livre, sem agarrar nada, sem ser agarrada por nada; e ali estava ele, sozinho, com as duas mãos livres, com as duas mãos disponíveis, no meio de uma enorme massa de gente que não parava de avançar [...] (TAVARES, 2015, p. 234-235).

Não temos a oportunidade de saber o que Hanna sente ou pensa ao perder-se de Marius. Isso aumenta a sua complexidade, pois a gama de interpretações desse fato torna-se ainda maior. Concluímos dizendo que Hanna é um exemplo de personagem da preferência de Wood, conforme o que ele diz nesse trecho: "Meu gosto pessoal pende para o personagem apenas esboçado, cujas omissões e lacunas nos intrigam, fazendo-nos entrar em suas superficialidades profundas" (WOOD, 2012, p. 95).

\section{REFERÊNCIAS}

BELTRÃO, L. M.; FERREIRA, T. M.; MOURA, F. Lugares da catástrofe: três espaços do horror em Gonçalo M. Tavares. Revista Decifrar. Manaus, GEPELIP-UFAM, v.4, n.8, 2016, p. 81-100.

CANDIDO, Antonio et al. A personagem de ficção. São Paulo: Perspectiva, 2007.

EIRAS, Pedro. O labirinto sem saída. Gonçalo M. Tavares e W. G. Sebald. In: Cadernos de Literatura Comparada. Porto, ILCML - FLUP, n. 34, 2016, p.379-389. 
FORSTER, E. M. Aspectos do romance. São Paulo: Globo, 2005.

SILVA, Jonatan. Os escombros de uma guerra interior. In: Jornal Rascunho, Curitiba, ed. 190. Disponível em: http://rascunho.com.br/24131-2/. Acesso em: 12. set. 2018.

TAVARES, Gonçalo M. Uma menina está perdida no seu século à procura do pai. São Paulo: Companhia das Letras, 2015.

WOOD, James. Como funciona a fiç̧ão. São Paulo: Cosac Naify, 2012.

Artigo recebido em: 07 de maio de 2018. Artigo aprovado em: 30 de julho de 2018. 